\title{
O português indígena sateré-mawé: um projeto de pesquisa sociolinguística
}

\author{
Hellen Cristina Picanço Simas ${ }^{1}$ \\ Programa de Pós-Graduação em Educação, Universidade Federal do Amazonas
}

Dante Lucchesi ${ }^{2}$

Programa de Pós-Graduação em Estudos de Linguagem, Universidade Federal Fluminense

Resumo: $O$ artigo apresenta uma proposta de pesquisa sociolinguística do português indígena sateré-mawé, situado no município de Parintins, no Estado do Amazonas, bem como seus primeiros resultados empíricos, com a identificação de aspectos da morfossintaxe dessa variedade linguística supostamente derivados do contato entre línguas. A pesquisa é baseada em uma amostra de fala vernácula coletada, de acordo com as técnicas de pesquisa de campo da Sociolinguística variacionista, nas comunidades indígenas, com 16 falantes bilíngues em sateré-mawé e português. O artigo também faz uma descrição socioeconômica, demográfica e etnográfica do povo sateré-mawé e discute o conceito de português indígena e as implicações do seu estudo para o conhecimento da diversidade etnolinguística do país e para o ensino de língua de português nas comunidades indígenas.

Palavras-chave: Português indígena; Sateré-mawé; Contato entre línguas; Bilinguismo; Morfossintaxe.

Title: Indigenous Portuguese Sateré-Mawé: a project of sociolinguistic research

Abstract: The paper presents a propose of a sociolinguistic research about Indigenous Portuguese Sateré-Mawé, located on Parintins, Amazonas State, as well as its first empirical findings, with the identification of morphosyntactic traces of that linguistic variety which are supposedly derived from language contact. The research is based on a sample of vernacular speech collected, according to the field research techniques of Variationist Sociolinguistics, in indigenous communities, with 16 bilingual speakers in Sateré-Mawé and Portuguese. The paper also makes a socioeconomic, demographic and ethnographic description of SateréMawé people and discusses the Indigenous Portuguese concept, as well as the implication of this study for understanding the country's ethnographic diversity and for Portuguese Language teaching in indigenous communities.

Keywords: Indigenous Portuguese; Sateré-Mawé; Language contact; Bilingualism; Morphosyntax.

\footnotetext{
${ }^{1}$ Doutora em Linguística pelo Programa de Pós-Graduação em Linguística da Universidade Federal da Paraíba (PROLING/UFPB), Professora do Programa de Pós-Graduação em Educação (PPGE/UFAM) e do Curso de Comunicação Social/Jornalismo da Universidade Federal do Amazonas (CCS/UFAM). Orcid: https://orcid.org/0000-0001-9637-6587. E-mail: india.parintintins@gmail.com.

${ }^{2}$ Doutor em Linguística (UFRJ, 2000), Professor Titular de Língua Portuguesa da Universidade Federal Fluminense (UFF), Bolsista de Produtividade em Pesquisa do CNPq, Nível 1-B (Proc.: 305053/2019-1). Orcid: http://orcid.org/0000-0002-8058-2658. E-mail: dante.lucchesi@gmail.com.
} 


\title{
Introdução
}

A situação linguística do Brasil encerra um paradoxo. ${ }^{3}$ Por um lado, o Brasil é um dos países de maior homogeneidade linguística do mundo, com pelo menos $98 \%$ de sua população sendo composta por falantes nativos do português, a imensa maioria, monolíngue. Por outro lado, o Brasil é um dos países que exibe uma das mais ricas diversidades linguísticas do planeta (LUCCHESI, 2015a). São cerca de 50 línguas de imigração, sendo as mais antigas, o alemão, o italiano e o japonês; e entre as mais recentes, encontram-se o crioulo haitiano e variedades do espanhol sul-americano. Porém, a maior riqueza linguística do país se concentra na região amazônica e no Planalto Central. São pelo menos 180 línguas indígenas, pertencentes a mais de vinte grupos genéticos distintos (RODRIGUES, 1993, p. 99). ${ }^{4}$

Infelizmente, a maioria das línguas indígenas brasileiras corre hoje um sério risco de extinção. Muitas delas só são dominadas perfeitamente pelos membros mais idosos das suas comunidades de fala. Além disso, muitos povos indígenas já perderam suas línguas nativas. ${ }^{5}$ Aryon Rodrigues fez o seguinte balanço das línguas indígenas brasileiras no final do século passado:

\begin{abstract}
[A maior língua indígena] não alcança 20.000 membros (tikúna). Com mais outras três (makuxí, teréna, kaingáng), constituem um grupo de quatro que contam com 10.000 membros ou mais. Outras vinte minorias linguísticas indígenas têm entre 1.000 e 10.000 falantes. As outras 156 línguas indígenas são faladas por menos de 1.000 pessoas cada uma. Em qualquer parte do mundo, elas seriam consideradas línguas fortemente ameaçadas de extinção. Quarenta dessas são faladas por menos de cem pessoas. (RODRIGUES, 1993, p. 100)
\end{abstract}

Embora tenha havido, nas últimas décadas, uma reação com ações de preservação e até revitalização de línguas indígenas, reforçada com processos de educação bilíngue, o quadro geral é muito desfavorável (MAIA, 2006; D’ANGELIS, 2014). Isso coloca a necessidade premente das pesquisas de descrição e documentação das línguas indígenas brasileiras remanescentes. Por outro lado, a situação linguística dos povos indígenas do Brasil também suscita outros objetos de estudo de grande interesse, com destaque para as variedades de português faladas por esses povos.

O estudo do que é denominado genericamente português indígena tem grande relevância social e significativo interesse científico, em função da importância de documentar e descrever essa dimensão pluriétnica da língua portuguesa no Brasil, como parte do

\footnotetext{
${ }^{3}$ Esta pesquisa foi feita em estágio de pós-doutorado no Programa de Pós-Graduação em Estudos de Linguagem, com bolsa do PNPD/CAPES.

${ }^{4}$ O Censo de 2010 do IBGE computou quase 900 mil indígenas na população brasileira ( 896,9 mil), que se distribuem por 305 etnias e falam 274 línguas. Mas o número de línguas indígenas existentes no Brasil está longe de ser consensual, até pela dificuldade inevitável de decidir se variedades linguísticas muito aproximadas constituem dialetos de uma mesma língua, ou línguas diferenciadas. [Fonte: IBGE, Censo 2010. Disponível em: https://censo2010.ibge.gov. br/noticias-censo?busca=1\&id=3\&idnoticia=2194\&t=censo-2010-poblacaoindigena-896-9-mil-tem-305-etnias-fala-274\&view=noticia. Acesso em: 25 maio 2020]

${ }^{5}$ Ainda segundo o Censo de 2010, só $37,4 \%$ dos indígenas com 5 anos ou mais falam uma língua indígena, e $76,9 \%$ falam o português. [Fonte: idem; ibidem.]
} 
patrimônio linguístico do país - estudo que tem uma aplicação prática no subsídio de políticas e estratégias de ensino de língua nessas comunidades. Essas variedades do português são faladas como segunda língua (L2) ou em situação de bilinguismo com a língua indígena; situações raras no cenário linguístico do país, majoritariamente monolíngue. A análise sociolinguística dessas comunidades de fala indígenas contribui, assim, para a compreensão dos processos estruturantes das situações em que uma língua hegemônica se impõe sobre línguas de povos em situação de vulnerabilidade, levando, em muitos casos, ao desaparecimento dessas línguas. Além disso, a análise estrutural dessas variedades de português faladas como L2, ou em situações de bilinguismo, pode iluminar a forma como o contato massivo entre línguas e a aquisição de segunda língua não sistemática pode afetar a estrutura da língua que se impõe na situação de contato (WINFORD, 2003; HICKEY, 2010; ROMAINE, 2010).

Ao longo da história sociolinguística do Brasil, a imposição do português a povos de línguas indígenas e africanas foi um processo geral, forçando esses povos a abandonar sua língua, dando origem às atuais variedades populares do português brasileiro (LUCCHESI, 2009a, 2015b). Assim, a análise da variação observada nas atuais variedades do português indígena pode iluminar igualmente os processos que determinaram a história da língua portuguesa no Brasil.

Este artigo descreve a implementação de um projeto de pesquisa sociolinguística de uma variedade do português indígena da região amazônica, bem como seus primeiros achados empíricos. Trata-se do português sateré-mawé, falado no município de Parintins, no Baixo Amazonas. A grande maioria dos sateré-mawé são bilíngues em sua língua nativa e português, sendo que os mais jovens estão adquirindo o português cada vez mais cedo. Como seu objetivo central, o projeto visa a realizar análises variacionistas de aspectos relevantes da morfossintaxe dessa variedade do português supostamente afetados pela situação de bilinguismo. Para tanto, foi coletada uma amostra de fala vernácula, seguindo os princípios metodológicos da Sociolinguística variacionista (LABOV, 2008), com a gravação de 16 entrevistas informais com membros da comunidade, divididos em quatro faixas etárias e pelos dois sexos.

Este artigo está estruturado da seguinte maneira. A primeira seção discute o conceito de português indígena. A segunda seção faz uma breve apresentação do povo sateré-mawé, em seus aspectos socioeconômicos, culturais e linguísticos. A terceira descreve a implementação do projeto de pesquisa sociolinguística junto aos sateré-mawé, em Parintins, Amazonas. E a quarta seção elenca características do português sateré-mawé que derivam do contato entre línguas. Trata-se dos primeiros achados de uma pesquisa que pretende contribuir para o conhecimento da realidade etnolinguística do país, bem como de sua história. 


\section{0 que é o português indígena?}

Basicamente, o português índio ou português indígena é uma variedade da língua portuguesa falada pelos povos indígenas brasileiros, seja por aqueles que ainda mantêm sua língua nativa, seja por aqueles que já a perderam. Entretanto, Terezinha Maher (1996, p. 212) argumenta que "falar de um português índio é, de um certo modo, uma generalização: mais correto seria falar em português apurinã, português kaxinawá, português shawãdawa, etc...", pois "cada uma destas variedades tem, certamente, a sua especificidade". Ainda segundo Maher (1998), mesmo os povos que perderam sua língua indígena não deixam de transpor sua cultura interacional para a língua portuguesa; daí a necessidade de ser mais específico na denominação dessas variedades de português, porque cada etnia, devido às transferências que faz da sua língua indígena para a língua portuguesa, imprime nesta as características linguísticas da sua língua materna.

Assim, uma denominação específica se impõe, não apenas pelas diferenças linguísticas que se podem observar entre as diversas variedades de português faladas pelos povos indígenas, mas também pelo respeito à identidade étnica própria de cada povo (FOUGHT, 2010). Contudo, isso não invalida a generalização teórica que conduz ao conceito genérico de português indígena, que se sustenta em uma grande interseção de características socioculturais e linguísticas comuns. Tais características comuns permitem reunir esse conjunto de falares em uma variedade mais geral, que, como toda variedade linguística considerada em sua dimensão sócio-histórica (como o português popular brasileiro, ou mesmo o português brasileiro), é heterogênea, estando a fortiori sujeita a ser dividida em subvariedades.

Do ponto de vista sociolinguístico, o português indígena se caracteriza por ser falado por grupos geralmente pouco numerosos, que se encontram em um processo de mudança de língua (language shift) da língua indígena para o português; constituindo um continuum que se estende desde as situações em que esse processo ainda é incipiente, até as situações em que ele já se completou, e a língua indígena desapareceu. Obviamente, a mudança de língua, com o desaparecimento da língua indígena, não é uma resultante inexorável, e é muito desejável que assim não seja. Porém, por crescentes pressões socioeconômicas (que se agravaram nos últimos anos), a maioria dos povos indígenas se encontra em situação de vulnerabilidade, com a conservação de sua cultura e seu modo de vida ameaçados, o que compromete a transmissão geracional de suas línguas (D'ANGELIS, 2014).

No plano socioeconômico, as comunidades indígenas que falam variedades da língua portuguesa, em diferentes níveis de assimilação e proficiência, vivem em graus variados de isolamento, tendo muitas vezes como principal atividade econômica o extrativismo e/ou a agricultura de subsistência. Essa definição contém uma série de parâmetros variáveis que devem ser considerados em uma análise sociolinguística de cada variedade de português indígena: (i) sua representatividade numérica; (ii) seu grau de isolamento/integração em relação à sociedade dominante; (iii) suas atividades econômicas. Esses parâmetros socioeconômicos, por sua vez, determinam parâmetros culturais e linguísticos que devem ser 
analisados e mensurados: (i) vitalidade da identidade étnica; (ii) conservação da cultura material e imaterial do povo indígena; (iii) conservação de sua língua; (iv) penetração do português na comunidade.

Todos esses parâmetros estão interligados. Quanto maior o isolamento, maior a conservação do modus vivendi e da cultura ancestral do povo, maior vitalidade de seu sentimento de identidade e de sua língua e menor penetração do português. No outro extremo, temos os povos muito integrados, aculturados, com baixo sentimento de pertencimento étnico, com a língua desaparecida ou em vias de desaparecimento, tendo como língua hegemônica o português. Entre os dois extremos, há todo um gradiente complexo e diversificado, pois não se pode pensar em termos de uma relação mecanicista entre os fatores objetivos e subjetivos, uma vez que um povo indígena não precisa estar isolado para conservar sua cultura e valorizar sua identidade étnica e a fortiori a sua língua nativa.

Sobretudo nas últimas décadas, tem havido uma reação, com movimentos de conservação e valorização da cultura e da identidade indígena, até com ações de restauração linguística (MAIA, 2006; ALMEIDA; RUBIM, 2012; D’ANGELIS, 2014). Porém, trata-se de uma reação proporcionalmente diminuta, diante de séculos de violência e dominação econômica, simbólica e cultural, que levou ao extermínio de povos inteiros, ou de processos violentos e devastadores de aculturação forçada, de modo que integração à sociedade dominante tem significado para os povos originários, no mais das vezes, exploração, espoliação, violência física e/ou simbólica, destruição do seu habitat, aculturação forçada, perda da identidade e da língua. A redução de mais de mil línguas indígenas faladas no território brasileiro, quando se iniciou a colonização portuguesa, no século XVI, para as menos de duzentas línguas atuais nada mais é do que reflexo dramático de um genocídio secular e de um processo forçado e devastador de aculturação, que, aviltando os padrões de comportamento do indígena, relativamente à sexualidade, ao trabalho, à indumentária, à religião e à língua, conduziam-no igualmente à sua desagregação identitária, à depressão e à morte (RODRIGUES, 1993; FREYRE, 2002).

E o fato de a maioria das línguas indígenas hoje correr sério risco de extinção significa que todo esse processo ainda está em curso, embora tenha sido um pouco mitigado, e programas e ações de resistência devam ser registrados pelo seu grande valor e significado, embora ainda muito reduzidos e limitados.

Assim sendo, o quadro geral do contato do português com as línguas indígenas deve ser definido como uma situação em que uma língua dominante em termos socioeconômicos e demográficos se impõe sobre uma língua minoritária, de modo que o português vai substituindo a língua indígena, progressivamente, nas diversas esferas de uso da língua, até o desaparecimento desta (HICKEY, 2010; ROMAINE, 2010). A base econômica desse processo é a desintegração do modus vivendi e da cultura ancestral do povo indígena e a integração dos seus membros no mercado de trabalho e de consumo da sociedade dominante. Do ponto de vista das funções de uso da língua, o português penetra como língua de comunicação com mundo exterior. Em seguida, passa a ser a língua de uso dos indivíduos que se integram no 
comércio ou nas atividades produtivas com a sociedade branca, bem como das crianças que se alfabetizam em português. Muitas vezes, os adultos passam a falar em português com os filhos ou incentivar neles o uso dessa língua, como meio para que eles possam se inserir melhor na realidade socioeconômica que se impõe. Assim, na situação mais comum, a língua indígena vai se restringindo em seu espectro funcional, e a proficiência nela vai decaindo, à medida que se passa para as gerações mais jovens, de modo que, no mais das vezes, os mais jovens só têm um conhecimento passivo ou dominam um reduzido vocabulário da língua dos seus ancestrais. Esboça-se aqui apenas um quadro muito geral que abstrai certos aspectos como, por exemplo, as situações de multilinguismo indígena, com casamentos interétnicos e/ou adoção de uma língua de outro povo indígena no qual um povo minoritário se integra, bem como os efeitos da miscigenação com os brancos.

Do que foi dito até aqui, pode-se concluir que a situação de cada variedade do português indígena vai variar bastante, consoante o grau de integração do povo que a fala, por um lado, e grau de conservação cultural e linguística desse povo, por outro. O português pode ser, desde a língua já hegemônica, ou mesmo única do povo indígena, até ser uma segunda língua adquirida e usada em graus variados de proficiência, em um espectro funcional igualmente variado; ou seja, podendo ser essa variedade bem restrita, em seu grau de proficiência e espectro funcional. Quanto mais situado nesse último polo, maiores serão os efeitos do contato linguístico, sobre essa variedade de português, sendo mais notáveis mesmo os processos de interferência ou de transferência da língua indígena para a língua portuguesa. ${ }^{6}$

Apesar das dificuldades e dos desafios que se colocam para o estudo do português indígena, houve significativos progressos da pesquisa nessa área. Nesse sentido, deve-se destacar o estudo pioneiro de Rosa Virgínia Mattos e Silva (1988) sobre o português kamayurá, com base no registro de conversas livres com bilíngues e de narrativas, colhidas entre agosto e setembro de 1969. Outro marco de grande relevância foi a pesquisa sociolinguística de Charlotte Emmerich (1992) sobre o português de contato do Parque Nacional do Xingu. No mesmo período, Juanacele Costa (1994) investigou as atitudes linguísticas de professores de língua portuguesa da rede pública de Águas Belas (PE) acerca do falar dos alunos oriundos da aldeia Fulni-ô. Ainda na década de 1990, Terezinha Maher (1996) analisou o português indígena que observou junto a professores apurinã, do Acre. Em seguida, os estudos de Cristina Gomes (1997) focalizaram o uso variável das preposições a, para, de, com e em também no português-kamayurá. No mesmo ano, Dante Lucchesi e Alzira Macedo (1997) publicam os resultados de uma análise variacionista da concordância de gênero no português de contato do Alto Xingu. Já neste século, Marília Ferreira (2005) levou a cabo a descrição do português falado pelos indígenas Parkatejê, do Estado do Pará.

Segundo Beatriz Christino e Moana Silva (2012, p. 4):

As pesquisas acerca de variedades do português brasileiro empregadas por comunidades indígenas já vêm trazendo contribuições interessantes para as investigações acerca das mudanças vinculadas ao contato entre línguas, ao mesmo

\footnotetext{
${ }^{6}$ Para uma discussão sobre a diferença entre interferência e transferência, veja-se Winford (2003).
} 
tempo em que vêm revelando fenômenos linguísticos que permitem uma melhor caracterização da diversidade linguística nacional.

As variedades de português indígena representam, com efeito, um importante elemento de identidade étnica (MAHER, 1996, 1998). Isso é inclusive reconhecido no Referencial Curricular Nacional para as Escolas Indígenas em 1998 (p. 123):

Os povos indígenas têm, cada um deles, o seu modo próprio de falar a língua portuguesa. Esses modos de falar o português têm, quase sempre, marcas muito específicas da língua de origem do povo em questão: no vocabulário, na gramática, na pronúncia. Esses modos de expressão devem ser respeitados na escola e fora dela, já que também são atestados de identidade indígena.

Portanto, para além de sua relevância social, nos termos dos subsídios que pode fornecer para políticas de educação indígena e de sua contribuição para o conhecimento da diversidade linguística do país, o português indígena constitui um objeto próprio e profícuo da pesquisa linguística, com suas implicações para o avanço do conhecimento do contato entre línguas, da variação e da mudança linguísticas e da história linguística do Brasil.

\section{O Povo Sateré-Mawé: localização, filiação linguística e aspectos culturais}

Os sateré-mawé habitam a terra indígena (TI) Andirá-Marau, localizada na região do Médio rio Amazonas, entre os estados do Amazonas e do Pará, cujo espaço territorial compreende 788.528 hectares, com perímetro de 477,7 km (TEIXEIRA, 2005). A TI pertence a três municípios amazonenses: Parintins (30.994 ha), Barreirinha (143.044 ha) e Maués (148.622 ha), e a dois municípios paraenses: Itaituba (350.615 ha) e Aveiro (115.253 ha). Esta terra indígena foi demarcada por portaria, publicada em 06 de maio de 1982 e homologada em 06 de agosto de 1986, após anos de muitos conflitos e lutas pelo espaço, período em que grande parte da população sateré-mawé foi exterminada. O povo sateré-mawé ocupa ainda uma pequena área dentro da terra indígena Koatá-Laranjal, no estado do Pará, espaço dividido com o povo Munduruku (TEIXEIRA, 2005).

O território indígena Sateré-Mawé divide-se em três grandes regiões: rio Andirá em Barreirinha, rio Waikurapá em Parintins e rio Marau-Urupadi em Maués. A região do Andirá pertence ao município de Barreirinha, onde ficam mais de 50 aldeias, com uma população de aproximadamente 3,8 mil pessoas. Na região do Marau-Urupadi, pertencente ao município de Maués, ficam aproximadamente 37 aldeias, com cerca de 3,3 mil sateré-mawé (TEIXEIRA, 2005), e na região do Uaikurapá, pertencente ao munícipio de Parintins, são apenas sete comunidades: São Francisco, com 172 habitantes; Nova Alegria, com 173 habitantes; Vila da Paz, com 140 habitantes; Vila Batista, com 331 habitantes; Nova Galileia, com 76 habitantes; Monte Carmelo, com 75 habitantes; e Ipiranga, com 110 habitantes Parintins (SIMAS; FERNANDES; PEREIRA, 2016).

Pery Teixeira (2005), com base no Censo Sociodemográfico realizado em 2003, afirma que a maioria dos sateré-mawé $(66 \%)$ que vivem atualmente no rio Waikurapá provém 
originariamente do rio Andirá. No entanto, $7 \%$ deles migraram primeiramente para o Koatalaranjal e só depois instalaram-se no rio Waikurapá. Outra parte da população (17\%) é originária do rio Marau-Urupadi, sendo que apenas $2 \%$ dos sateré-mawé que residem no rio Waikurapá são naturais de lá. Os 15\% restantes têm origens diferentes das citadas, ainda segundo Teixeira.

A FUNAI estima que cerca de 519 sateré-mawé residam na área urbana de Parintins, sendo que aproximadamente 100 desses indígenas residem fixamente na casa de trânsito da cidade, situada na Rua Silva Campos, centro, Parintins (SIMAS; FERNANDES; PEREIRA, 2016). $O$ restante dos sateré-mawé vivem em casas localizadas nos bairros periféricos da cidade, sobrevivendo como mão de obra barata no mercado de trabalho informal.

Inúmeros foram os fatores para que o povo sateré-mawé se expandisse pelas regiões citadas, a saber: as missões de catequização impostas pelos jesuítas; os conflitos enfrentados ao lado dos Munduruku e dos Mura pela defesa de seu território; as devastações em seus territórios ancestrais; e as perseguições ao seu povo que combatia ao lado dos cabanos (TEIXEIRA, 2005). Por outro lado, como a maioria dos povos indígenas da região os saterémawé também padeceram com as buscas incessantes dos colonizadores pelas drogas do sertão, a exploração da borracha e as inúmeras epidemias trazidas pelos não indígenas. Atualmente, observa-se um significativo movimento migratório dos membros desse povo para os centros urbanos, em busca de melhores condições de saúde, educação e trabalho.

\section{Filiação linguística}

Cerca de 13.310 pessoas falam a língua sateré-mawé, da família linguística mawé, do tronco Tupi ${ }^{7}$. Aryon Rodrigues (1986, p. 100), em seus primeiros estudos sobre o Tupi, classificou a língua sateré-mawé como pertencente à família linguística tupi-guarani:

Mas uma análise léxico-estatística do vocabulário básico do mawé demonstra a presença de quase $50 \%$ de elementos tupi-guarani, o que depõe decisivamente em favor de sua filiação à família tupi-guarani. Este resultado confirma a opinião de Curt Nimuendajú sobre o mawé, isto é, de que se trata fundamentalmente de língua tupi, embora se diferencie do guarani-tupinambá.

Depois, porém, entendeu que era um equívoco tal classificação:

Até agora tanto o aweti quanto o mawé vinham sendo incluídos na família tupiguarani. O melhor conhecimento de ambos deixa claro, entretanto, que são tão aberrantes, cada uma a sua maneira, em relação a todas as outras línguas incluídas naquela família, que sua associação com elas deve ser procurada em outro plano" (RODRIGUES, 1984/85, p. 35).

Também há duas hipóteses sobre a língua sateré-mawé no que diz respeito à sua formação. A primeira é sustentada por Rodrigues e Dietrich (1997), para quem existia dentro

\footnotetext{
${ }^{7}$ Fonte: IBGE. O Brasil Indígena. Disponível em:

https://indigenas.ibge.gov.br/images/pdf/indigenas/folder indigenas web.pdf. Acesso em: 13 jun. 2020.
} 
do tronco tupi um ramo composto por mawé, aweti e proto tupi-guarani (PTG). No entanto, ocorreu uma primeira mudança: a família mawé se separou do ramo, depois houve a separação entre aweti e PTG, formando a configuração atual de famílias linguísticas do tronco tupi, a saber: arikén, aweti, juruna, munduruku, mawé, mondé, puroborá, ramarána, tupari e tupi-guarani. A segunda hipótese é sustentada por Drude (2006): como não houve mudanças linguísticas significativas entre mawé, aweti e proto tupi-guarani, a separação entre elas foi simultânea ou muito próxima, opondo-se à hipótese de Rodrigues e Dietrich (1997).

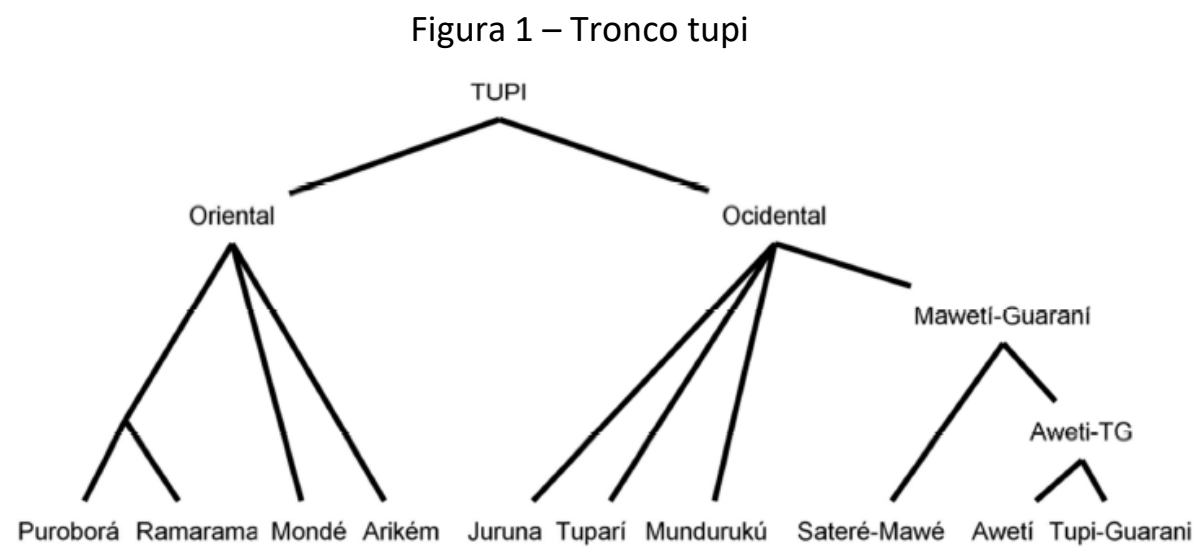

Fonte: Cruz (2011, p. 28).

Para Raynice Silva (2010, p. 61), o sateré-mawé apresenta muita influência da língua nheengatu: "é importante considerar ainda que a língua Sateré-Mawé sofreu acentuada influência lexical do Nheengatu, principalmente na região do rio Andirá, desde o início do século XVII". Para a autora, no léxico da língua sateré-mawé, existem palavras vindas do nheengatu por empréstimo, como por exemplo: apukuita 'remo', kuia 'cuia', jakare 'jacaré', kumana 'feijão', purure 'enxada' e, em menor quantidade, vindas por neologismo tais como:

Quadro 1 - Comparação entre as línguas sateré-mawé e nheengatu

\begin{tabular}{|ccc|}
\hline Sateré-mawé & Nheengatu & Significado \\
\hline [awati] & [awatSi] & 'milho' \\
[tupana] & [tupã] & 'Deus/divindade \\
[muka] & [mukawa] & 'espingarda' \\
[pisanã] & [pifana] & 'gato' \\
\hline
\end{tabular}

Fonte: Silva (2010, p. 62).

A autora ressalta que teve dificuldade em determinar se os empréstimos vieram diretamente do nheengatu ou se a partir da língua portuguesa, uma vez que algumas palavras existentes em língua portuguesa são empréstimo da língua nheengatu. Atualmente, a língua sateré-mawé não está mais em contato com a língua nheengatu, mas sim com a língua portuguesa, principalmente as comunidades mais próximas às cidades. 
O guaraná, o porantin e o ritual da tukandeira: símbolos da identidade sateré-mawé

Os sateré-mawé se consideram filhos do guaraná (waraná, em língua sateré-mawé). Essa planta silvestre foi descoberta e semidomesticada por este povo, configurando-se como um dos símbolos da identidade sateré-mawé. Segundo as suas tradições, o waraná contém o princípio do wara, isto é, o ponto de início de todo conhecimento. A bebida feita com waraná em pó com água, após passar pelos processos de secagem, torragem e moagem, é consumida diariamente em situações de rituais, ou não, pelos indígenas.

Nas comunidades sateré-mawé, a coleta do fruto é artesanal e seu beneficiamento e sua comercialização atualmente são feitos principalmente pelo Consórcio dos Produtores Sateré-Mawé (CSPM), formado por 500 famílias Sateré-Mawé, localizado na cidade de Parintins - AM (CSPM, 2018).

Figura 2 - Fruto Guaraná

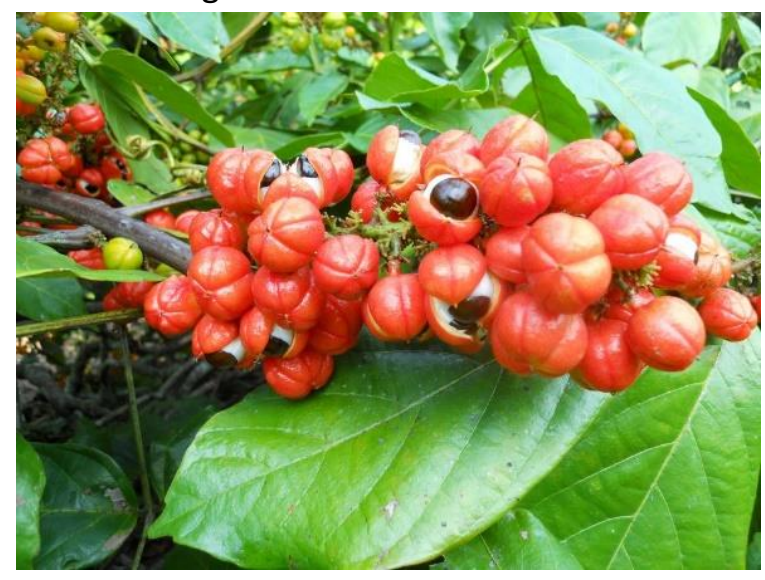

Fonte: CSPM, 2020.
Figura 3 - Beneficiamento do guaraná

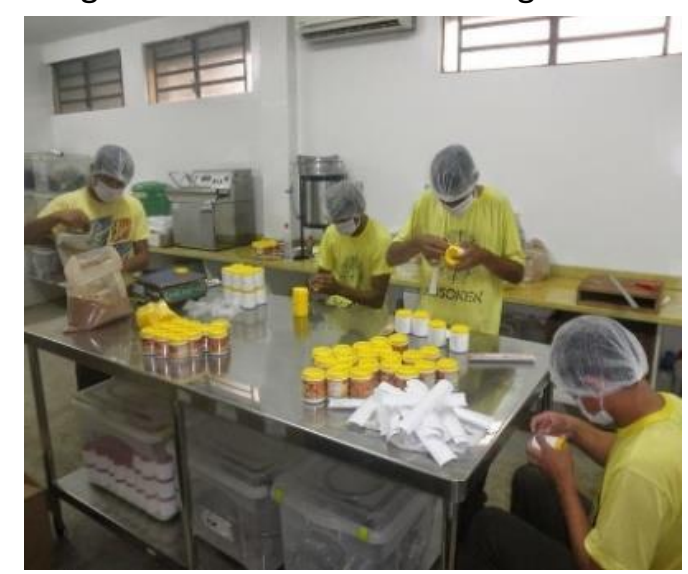

Fonte: CSPM, 2020.

O guaraná tem importância muito grande não só para o povo sateré-mawé, mas para o estado do Amazonas. A produção, que abrange toda a área da terra indígena Andirá-Marau, é muito requisitada pelas empresas do ramo de refrigerante e de energético. Para o povo sateré-mawé, o waraná, além da importância econômica, possui importância simbólica, por isso entende que a bebida é sagrada.

Outro elemento da identidade étnica sateré-mawé é o remo sagrado nomeado Porantin. Em cada lado do remo, estão escritas as leis que o povo sateré-mawé deve seguir. Podemos compará-lo à tábua dos dez mandamentos. No entanto, num lado do remo, estão escritas as coisas boas e do outro lado as coisas más, as quais não devem ser realizadas. Possui grafismos que narram a origem do povo sateré-mawé. "É ele que prevê os acontecimentos, aparta desavenças e soluciona conflitos internos" (UGGÉ s/d).

Segundo relato do senhor Douglas Sateré, 47 anos, em entrevista feita em 2018, existem dois remos sagrados, cada um está em uma aldeia diferente, uma no rio Marau e outra no rio Andirá. No entanto, só um deles é o verdadeiro, segredo guardado por alguns anciões. Só algumas pessoas podem vê-lo, têm que ter merecimento e idade superior a 50 
anos para ver o Porantin, relatou o entrevistado. O segredo do Porantin é passado de geração a geração pelo ancião, que, na iminência da morte, repassa o conhecimento ao seu filho homem primogênito.

Por fim, o ritual da tukandeira é outro símbolo que marca a identidade étnica saterémawé. Este ritual de iniciação masculina consiste em o jovem meter as mãos em luvas tecidas com palha e cheias de formigas tukandeira, pelo tempo de canto de uma música executada no ritual. As formigas dão ferroadas muito dolorosas, mas o jovem precisa mostrar coragem, força e resistência. Cumprindo a realização do ritual vinte vezes, dez para cada mão, é reconhecido como guerreiro e está apto, por exemplo, a casar.

O jovem que passa pelo ritual precisa também cumprir uma dieta, alimentando-se das formigas que o ferraram. As tukandeiras são fritas sem sal e colocadas em chibé de farinha. Por oito dias seguidos, o jovem é ferrado e se alimenta das formigas e de pirão. Não poderá comer sal e ingerir outro tipo de alimento. Após os oitos dias de ritual, os jovens vão caçar macaco velho para preparar sua refeição, é quando têm um descanso das ferradas. A partir desse alimento, o jovem já poderá comer com bem pouco sal. Também nesta etapa do rito, três jovens virgens são escolhidas: a primeira para arranhar o corpo do jovem iniciado com osso de paca; a segunda para colocar sal na sua boca; e a terceira para passar no corpo do jovem guerreiro uma raiz ralada chamada catauari, a qual arde como pimenta. Todo esse processo é repetido em outra oportunidade. Depois disso, pode se submeter ao ritual por vontade própria, não é mais obrigado.

Segundo Elcidio Sateré, 35 anos (entrevista, realizada em 2017), as ferradas da tukandeira são a vacina do indígena sateré-mawé. Para ele, quem passa pelo ritual está protegido de doenças. Quem começar o ritual e não terminar será perseguido pelas formigas, em sonho, e começará a ficar sem vontade de trabalhar, se alimentar etc. A barriga começará a crescer, e ficará cheia de tukandeira. "Ela vai emprenhar o homem", dizem os mais velhos.

O ritual é realizado principalmente nas comunidades mais antigas, ou seja, as que se localizam mais próximas às aldeias originárias do sateré-mawé, no rio Andirá e Marau, bem distantes dos centros urbanos. Devido à atuação principalmente das igrejas evangélicas, particularmente a Adventista, o ritual da tukandeira não é mais realizado nas comunidades com forte influência evangélica, pois a prática é condenada por essa religião. Também o ritual vem sendo abandonado em algumas aldeias, devido à influência da cultura urbana das cidades próximas às comunidades sateré-mawé.

\section{Nomeação do Povo Sateré-Mawé: algumas definições}

Há três versões para o nome do povo Sateré-Mawé. A mais conhecida é a de que sateré significa "lagarta de fogo" e é referência ao clã mais importante dentre os que compõem o povo indígena sateré-mawé. É o clã que indica tradicionalmente a linha sucessória dos chefes políticos. O segundo nome, mawé, significa "papagaio inteligente e curioso", não sendo designação clânica (TEIXEIRA, 2005, p. 21). A segunda versão é de que uma liderança, cujo clã é o sateré, foi a Brasília representar seu povo. Na hora em que foi questionada qual o nome 
do seu povo, respondeu sateré, porque entendeu que estavam questionando o nome de seu clã. Mawé ficou como referência ao local geográfico a que a liderança pertencia, no caso, o município de Maués. Assim, por esse desentendimento na comunicação, o povo ficou conhecido pelo não indígena como sateré-mawé, segundo esta versão. A última explicação para o nome sateré-mawé, obtida em conversa informal com liderança sateré é a de que nome do povo é mari. Neste trabalho, adotou-se o nome sateré-mawé, por ser o mais conhecido na literatura acadêmica.

\section{A pesquisa de campo: constituição da amostra linguística}

Para fornecer a base empírica para a descrição e análise sociolinguística da língua sateré-mawé, foi colhida uma amostra de fala vernácula, nas comunidades sateré-mawé de Nova Alegria e Vila Batista, localizadas no rio Waicurapá, município de Parintins, Estado do Amazonas. Para chegar a essas aldeias, é necessário realizar viagem em barco de linha, com duração de 5 horas, ou realizar viagem de voadeira fretada, com duração média de 2 horas. A população de cada comunidade é de 331 pessoas, em Vila Batista, e 181 pessoas, em Nova Alegria.

Há, em cada aldeia, uma escola municipal de educação escolar indígena, responsável pela educação da pré-escola ao ensino médio; este, à distância. A comunidade recebe abastecimento de luz e de água, apesar desses serviços não serem regulares, ocorrendo bastante a falta de abastecimento de água e de energia elétrica, segundo os moradores. Além da plantação do waraná, a comunidade sobrevive com a economia de subsistência, fazendo roças, nas quais seus membros plantam mandioca, cará, banana, laranja, maniva etc. Produzem farinha, beiju, tucupi, criam galinha, caçam e pescam.

Em Vila Batista, já há uma igreja evangélica denominada Batista do Sétimo Dia. Em Nova Alegria, seus moradores estão tentando conseguir recursos para construir uma igreja também dessa mesma religião. Em cada aldeia, há um tuisá, ou seja, líder responsável por dirimir problemas da comunidade e representar seu povo nas assembleias gerais ou em ações junto ao poder público. Essa liderança é passada de pai para filho.

\section{Universo da Pesquisa e Estratificação e Constituição da Amostra Linguística}

O universo da pesquisa é a comunidade de fala sateré-mawé, constituída por 13.310 falantes da língua sateré-mawé ${ }^{8}$. Grande parte desses falantes é bilíngue na língua do grupo étnico e português. A maior proporção de falantes da língua indígena encontra-se nas aldeias: $95,9 \%$ falam sateré-mawé em contexto de terra indígena, enquanto apenas 54,9\% falam sateré-mawé no contexto urbano. Não há diferenças linguísticas entre as mulheres e os homens; entre aquelas, 95,9\% falam a língua indígena, enquanto o percentual de falantes da

\footnotetext{
${ }^{8}$ Fonte: IBGE. O Brasil Indígena. Disponível em:

https://indigenas.ibge.gov.br/images/pdf/indigenas/folder indigenas web.pdf. Acesso em: 13 jun. 2020.
} 
língua indígena entre os homens é de $96,1 \%$. No entanto, quando se considera o uso da língua portuguesa pelos sexos, a situação linguística muda bastante: $72,2 \%$ dos homens falam português, enquanto apenas 54,4\% falam essa língua (TEIXEIRA, 2005).

Porém, a situação linguística de cada comunidade sateré-mawé é diferente: há comunidades em que a L1 é a língua sateré-mawé e a L2 é a língua portuguesa; em outras, é o contrário, o português é a L1, e a língua indígena é a L2. O grau de proficiência também é variável de comunidade para comunidade, assim como a fluência por faixa etária.

No universo de falantes sateré-mawé, colheu-se uma amostra de fala vernácula com 16 indivíduos bilíngues, com o sateré-mawé como L1 e o português como L2, distribuídos pelos dois sexos e por quatro faixas etárias: Faixa I: 15 a 25 anos; Faixa II: 35 a 45 anos; Faixa III: de 55 a 65 anos; Faixa IV: mais de 65 anos, como apresentado no seguinte quadro:

Tabela 2 - Amostra de Fala Vernácula do Português sateré-maw
\begin{tabular}{|ll|}
\hline Faixa Etária & $\begin{array}{l}\text { Língua indígena L1 e } \\
\text { português L2 ou bilíngues }\end{array}$ \\
\hline 15 a 25 anos & 2 homens \\
& 2 mulheres \\
35 a 45 anos & 2 homens \\
& 2 mulheres \\
55 a 65 anos & 2 homens \\
& 2 mulheres \\
Mais de & 2 homens \\
65 anos & 2 mulheres \\
\hline
\end{tabular}

Fonte: elaborada pelos autores.

Além dessas entrevistas, foram feitas mais seis entrevistas (duas de caixa faixa etária), como corpus reserva. Cada entrevista teve a duração mínima de 40 minutos e a máxima de 60 minutos, nas quais se tratou de assuntos relacionados à vida na comunidade, buscando-se descontrair o informante, usando as técnicas da pesquisa sociolinguística para vencer o paradoxo do observador e extrair uma amostra do vernáculo do falante, ou seja, a fala mais informal possível nas circunstâncias de gravação de uma entrevista (LABOV, 2008). Em sua totalidade, somam mais de 720 minutos de gravação do português vernáculo sateré-mawé. Esse conjunto de entrevistas constitui o Acervo do Português Vernáculo dos Sateré-Mawé de Parintins, que passaram a integrar o acervo do Projeto Vertentes - UFBA e do Núcleo de Estudos de Linguagem da Amazônia - UFAM. As gravações foram somente em áudio e foram transcritas conforme a chave de transcrição desenvolvida e utilizada no Projeto Vertentes, da UFBA, ${ }^{9}$ com utilização programa Transcriber.

\footnotetext{
${ }^{9}$ Chave de Transcrição elaborada por Dante Lucchesi e está disponível em:

http://www.vertentes.ufba.br/projeto/transcricao. Acesso em: Acesso em: 13 jun. 2020.
} 


\section{Perfil dos sujeitos da pesquisa}

Foram escolhidos, prioritariamente, indivíduos com baixa ou nenhuma escolaridade, bilíngues, que têm a língua indígena como L1. O perfil dos entrevistados é apresentado a seguir

Tabela 3 - Perfil entrevistados

\begin{tabular}{|c|c|c|c|c|c|}
\hline & INF. & IDADE & SEXO & ESCOLARIDADE & COMUNIDADE \\
\hline FAIXA & 01 & 18 & $\mathrm{M}$ & Ensino Médio & Nova Alegria \\
\hline ETÁRIA I & 02 & 24 & M & Ensino Médio & Vila Batista \\
\hline \multirow[t]{2}{*}{ 15-25 anos } & 03 & 25 & $\mathrm{~F}$ & Ensino Médio Cursando & Nova Alegria \\
\hline & 04 & 22 & $\mathrm{~F}$ & Ensino Médio & Nova Alegria \\
\hline \multirow{5}{*}{$\begin{array}{c}\text { FAIXA } \\
\text { ETÁRIA I } \\
\text { 25-45 anos }\end{array}$} & 05 & 34 & $M$ & 4a série do Ensino & Nova Alegria \\
\hline & & & & Fundamental & \\
\hline & 06 & 43 & M & Ensino Médio & Nova Alegria \\
\hline & 07 & 35 & $\mathrm{~F}$ & Ensino Fundamental - EJA & Nova Alegria \\
\hline & 08 & 42 & $\mathrm{~F}$ & Ensino Fundamental & Nova Alegria \\
\hline \multirow{6}{*}{$\begin{array}{c}\text { FAIXA } \\
\text { ETÁRIA III } \\
55-65 \text { anos }\end{array}$} & 09 & 52 & $M$ & 2a série do Ensino & Vila Batista \\
\hline & & & & Fundamental & \\
\hline & 10 & 57 & M & $\begin{array}{l}\text { Ensino Fundamental } \\
\text { Incompleto }\end{array}$ & Nova União \\
\hline & 11 & 61 & $\mathrm{~F}$ & 9o ano - EJA & Nova Alegria \\
\hline & 12 & 60 & $\mathrm{~F}$ & 3ạ série do Ensino & Aratikun Novo \\
\hline & & & & Fundamental - EJA & \\
\hline \multirow{5}{*}{$\begin{array}{c}\text { FAIXA } \\
\text { ETÁRIA IV } \\
65+ \\
\text { Anos }\end{array}$} & 13 & 76 & $\mathrm{M}$ & Nunca Estudou & Nova Alegria \\
\hline & 14 & 93 & M & Estou bem pouco & Vila Batista \\
\hline & 15 & 67 & $\mathrm{~F}$ & 4a série do Ensino & Ponta Alegre \\
\hline & & & & Fundamental & \\
\hline & 16 & 72 & $\mathrm{~F}$ & Nunca estudou & Vila Batista \\
\hline
\end{tabular}

Fonte: elaborada pelos autores.

A baixa escolaridade não foi encontrada na faixa etária I, por isso, todos os informantes têm ensino médio ou estão cursando. Nas faixas etárias II e III, o nível de escolaridade dos informantes é mais baixo, somente um tem ensino médio, os demais cursam ou cursaram somente ensino fundamental ou parte dele. Na faixa etária IV, estão os que possuem nível de escolaridade mais baixo, um informante estudou até a 4a série do ensino fundamental, dois nunca estudaram e um só soube informar que estudou bem pouco. Não há diferença significava entre homens e mulheres quanto ao nível de instrução. 


\section{Etapas da pesquisa}

A etapa preliminar da pesquisa consistiu no levantamento dados sobre o povo saterémawé e na identificação do perfil sociolinguístico das suas comunidades em Parintins, tomando como base os dados demográficos e linguísticos disponíveis nos órgãos públicos: Fundação Nacional do Índio - FUNAI, Distrito de Saúde Indígena - DSEI e Instituto Brasileiro de Geografia e Estatística - IBGE. A partir desse levantamento, foram selecionados os participantes desta pesquisa. ${ }^{10}$ Depois, foram feitas duas viagens a campo para coletar a amostra do vernáculo. Em seguida, foram realizadas as transcrições grafemáticas das entrevistas. Por fim, analisou-se a fala vernácula dos sateré-mawé. Nesta primeira análise, buscou-se identificar as características proeminentes do português sateré-mawé, no nível da morfossintaxe.

\section{Características proeminentes do português indígena sateré-mawé}

A simplificação morfológica de uma variedade de $L 2$, que atinge sobretudo afixos flexionais e regras de concordância nominal e verbal, é comum nas situações de bilinguismo e de mudança de língua (language shift), nas quais os falantes de uma língua minoritária adquirem uma língua dominante como $L 2$, em situações naturais de aquisição não tutorada. Tais processos de simplificação são intensdificados pela falta de convergência entre a L1 e a L2, podendo ocorrer também interferências ou transferências da L1 sobre a L2 (WINFORD, 2003; TRUDGILL, 2009, 2010; MATRAS, 2010). Resultados desse tipo podem ser identificados no português sateré-mawé (PSM).

No que concerne aos processos de simplificação que resultam em uma ampla variação no emprego das regras de concordância nominal e verbal, há uma grande coincidência com processos gerais no português popular brasileiro (PPB) como um todo. Isso se explica pelo fato das variedades populares do português brasileiro se originarem precipuamente na aquisição defectiva do português como L2 por milhões de indígenas aculturados e africanos escravizados, seguida da nativização dessa variedade de português L2 entre os seus descendentes, nos primeiros séculos de formação da sociedade brasileira (LUCCHESI, 2009a, 2012, 2015b, 2019).

Assim como no PPB como um todo, registra-se no PSM uma ampla variação na concordância de número no sintagma nominal (SN): ${ }^{11}$

(1) Tá velhinho, quase já cem ano.

(2) Eu falava com meus primo, meus tio.

\footnotetext{
${ }^{10}$ Esta pesquisa de campo foi feita com autorização oficial da FUNAI e dos líderes indígenas das comunidades onde a amostra linguística foi coletada. Além disso, cada entrevistado assinou um Termo de Consentimento Livre e Esclarecido, nos moldes e condições requeridos para esse tipo de pesquisa. A pesquisa está inscrita na Plataforma Brasil, sob o número CAAE: 91492618.9.0000.5020.

${ }^{11}$ Todos os exemplos apresentados nesta seção foram retirados das entrevistas realizadas nesta pesquisa.
} 
(3) Os médico não tem do que se quexá.

Outro fenômeno geral no PPB que também se repete no PSM é variação na concordância verbal, junto a sujeitos na $1^{\text {a }}$ e na $3^{\text {a }}$ pessoa do plural:

(4) Com certeza, nós tem que concorda.

(5) Eles entende.

Há, porém, outros fenômenos variáveis que foram observados no PSM e não são gerais no PPB, só ocorrendo em variedades desse último que passaram por um processo mais radical de contato entre línguas, como o português afro-brasileiro (PAF) (LUCCHESI; BAXTER; RIBEIRO, 2009). Entre esses fenômenos, encontra-se a variação na concordância nominal de gênero, tanto no interior do SN, quanto no predicativo:

(6) Tem alguns família católica.

(7) É o função de uma liderança dentro da aldeia.

(8) E tu vai comê tukandeira assado.

(9) Lá no último rua que tem lá pra trás.

(10) Uma agente indígena, né, que geralmente foi escolhido pelo próprio tuxaua.

(11) Foi o tempo que minha irmã, né, é levado pra Manaus pra estudá.

Verifica-se uma ampliação do escopo da variação também na concordância verbal, ocorrendo a variação na concordância junto à 1a pessoa do singular, que normalmente não ocorre no PPB - com exceção também para o PAF (LUCCHESI; BAXTER; SILVA, 2009):

(12) Eu pretende ajuda a comunidade.

(13) Eu fala bem o português, é verdade.

Ainda no que concerne à categoria gramatical de número, identificou-se no PSM o uso do quantificador tudo, em sua forma neutra, como pluralizador nominal, como também foi observado no PAF (LUCCHESI, 2009b):

(14) Tudo nossa casa tem água encanada.

Uma construção que chega a ser agramatical para um falante urbano do português, mas é típica das línguas crioulas e da linguagem infantil (BICKERTON, 1981), é a dupla negação com sujeito, também presente no PSM:

(15) Ninguém somo mestiço não.

Outras características que foram identificadas no PSM não são encontradas em qualquer outra variedade do PPB, com destaque para a ausência de preposição nas seguintes estruturas.

Para indicar finalidade em orações reduzidas:

(16) Antes a FUNAI dava apoio abrir um comunidade. (para abrir)

Em adjuntos:

(17) Só mulhé menstruação que não pode. (mulher com menstruação) 
(18) Dão remédio pra eu... remédio pressão, só. (remédio para pressão)

(19) Agora já tem roupa pra lavá máquina, né? (na máquina)

Uma outra característica de línguas crioulas encontrada no PSM foi a ausência de verbos copulativos (MICHAELIS, 2013):

(20) Então a família da mamãe, da papai muito grande. (era muito grande)

(21) Minha filha agente de saúde, ganha bem. (é agente de saúde)

A variação também atinge bastante a flexão verbal de tempo, modo e aspecto, com o emprego da forma básica do presente em contexto de passado:

(22) Foi o tempo que minha irmã, né, é levado pra Manaus pra estudá. (era)

(23) Ás vez, eu fico falando com minha esposa... (ficava)

Essas características mais marcantes do PSM, que não se encontram em qualquer outra variedade do PPB, podem ser atribuídas a diferenças estruturais e tipológicas entre a língua sateré-mawé e a língua portuguesa, o que se buscará demonstrar em futuras análises, que focalizarão cada um desses aspectos gramaticais específicos do PSM. De qualquer forma, isso reforça a visão apresentada na primeira seção deste artigo de que cada variedade do português indígena é única, em função sobretudo das particularidades da língua que é falada por aquele povo indígena.

Por outro lado, essas características são típicas de estágios iniciais de processos de aquisição de segunda língua (ASL), sobretudo em situações não tutoradas, como demonstrado em estudo com trabalhadores imigrantes na Europa ocidental, que identificou essas características no que denominou variedade básica (PERDUE, 1993a e 1993b). É curioso encontrar essas características em falantes, em princípio bilíngues, que dominam o português há muitos anos. Isso revela que, em situações de bilinguismo situadas na periferia da sociedade, processos típicos dos estágios iniciais da ASL podem se manter como característica de comunidades bilíngues.

\section{Considerações finais}

O estudo das variedades de português faladas pelos povos indígenas brasileiros constitui uma das frentes mais profícuas e ainda pouco exploradas da pesquisa linguística no Brasil, como se buscou demonstrar neste artigo. Foi descrita a implementação de um projeto de pesquisa sociolinguística sobre o português falado pelo povo sateré-mawé, no Estado do Amazonas, apresentando os primeiros achados empíricos desta pesquisa. Esses achados revelaram as características mais proeminentes dessa variedade de português indígena, no nível da morfossintaxe.

Embora o PSM apresente características que são gerais ao PPB (o que não é surpreendente, na medida em que o português indígena deve ser considerado uma variedade do PPB, em seu espectro mais amplo), essa variedade linguística também exibe características que não se encontram em qualquer outra variedade do PPB. Tais características específicas 
podem ser o reflexo de características estruturais e tipológicas da língua sateré-mawé, particularmente quando ocorre a falta de convergência entre essa língua e o português. Por outro lado, algumas dessas características são típicas de línguas crioulas e/ou de estágios iniciais de ASL.

Portanto, os estudos do português indígena podem ampliar a conhecimento acerca das situações de contato linguístico massivo, bem como da ASL; e, com isso, reunir elementos para uma melhor compreensão de nossa história sociolinguística, marcada pelo contato massivo da língua portuguesa com povos indígenas e africanos. Esses serão objetivos colimados em futuras análises variacionistas, com suporte quantitativo, dos fenômenos morfossintáticos que individualizam o português indígena sateré-mawé.

\section{Referências}

ALMEIDA, A. W. B. de; RUBIM, A. C. Kokama: a reconquista da língua e as novas fronteiras políticas. Revista Brasileira de Linguística Antropológica, v. 4, n. 1, p. 67-80, 2012. https://doi.org/10.26512/rbla.v4i1.20669

BICKERTON, D. Roots of language. Ann Arbor: Karoma, 1981.

BRASIL. Ministério da Educação. Referencial Curricular Nacional para as Escolas Indígenas. Brasília: MEC, 1998.

CHISTINO, B.; SILVA, M. Concordância verbal e nominal na escrita em Português-Kaingang. Papia, v. 22, n. 2, p. 415-428, 2012.

COSTA, Januacele Francisca da. Bilinguismo e Atitudes Linguística Interétnicas: Aspectos do Contato Português-Ya:thê. 1993. 148 f. Dissertação (Mestrado em Letras) - Universidade Federal de Pernambuco, 1993.

CRUZ, A. Fonologia e Gramática do Nheengatú: a língua geral falada pelos povos Baré, Warekena e Baniwa. 2011. 233 f. Tese (Doutorado em Linguística) - Vrije Universiteit, Amsterdam, 2011.

CSPM. Nossa unidade de beneficiamento. Disponível em: https://photos.google.com/share/AF1QipPUSoFvQxtwJbRIIIwZx3qVMOU04BgxooxWyAdiwDLNZFosH6cfN8yz6WqsWVJug?key=MEtDd1FIbDVHUW1 OcXg2dC1HeGZzZXhYUXFjaGh3. Acesso em 23 set. 2020.

D’ANGELIS, W. R. Línguas Indígenas no Brasil: urgência de ações para que sobrevivam. In: BOMFIM, A. B.; COSTA, F. V. F. da (orgs). Revitalização de língua indígena e educação escolar indígena inclusiva. Salvador: Egba, 2014. p. 93-117.

DRUDE, S. On the position of the Awetí language in the Tupi family. In: DIETRICH, W.; SYMEONIDIS, H. (Eds). Guaraní y Maweti-Tupi-Guaraní. Berlin: Lit Verlag, 2006. p. 11-45.

EMMERICH, C. O português de contato no Parque Indígena do Xingu. Estudos Linguísticos e Literários, n. 13, p. 57-90, 1992.

FERREIRA, M. Descrição de aspectos da variante étnica usada pelos parkatêjê. DELTA, v. 21, n. 1, p. 1-21, 2005. https://doi.org/10.1590/S0102-44502005000100001 
FOUGHT, C. Ethnic Identity and Linguistic Contact. In: HICKEY, R. (ed.). The Handbook of Language Contact. Chichester: Wiley-Blackwell, 2010. p. 282-298. https://doi.org/10.1002/9781444318159.ch14

FREYRE, G. Casa Grande \& Senzala: formação da família brasileira sob o regime de economia patriarcal. In: SANTIAGO, S. (Coord.). Intérpretes do Brasil. Vol. 2. Rio de Janeiro: Nova Aguilar, 2002. p. 121-645.

GOMES, C. A. A importância do significado da preposição na aquisição de segunda língua. Papia, v. 9, p. 65-71, 1997.

HICKEY, R. Contact and Language Shift. In: HICKEY, R. (ed.). The Handbook of Language Contact. Chichester: Wiley-Blackwell, 2010. p. 151-169.

https://doi.org/10.1002/9781444318159

INSTITUTO AMAZONIA. Pesquisas avançam para melhorar o cultivo do guaraná no Amazonas. Disponível em: https://www.institutoamazonia.org.br/pesquisas-avancam-para-melhorar-ocultivo-do-guarana-no-amazonas/. Acesso em: 09 ago. 18.

LABOV, W. Padrões Sociolinguísticos. São Paulo: Parábola, 2008.

LUCCHESI, D. História do Contato entre Línguas no Brasil. In: LUCCHESI; D.; BAXTER, A.; RIBEIRO, I. (orgs.). O Português Afro-Brasileiro. Salvador: Edufba, 2009a. p. 41-73. https://doi.org/10.7476/9788523208752

LUCCHESI, D. A concordância de gênero. In: LUCCHESI; D.; BAXTER, A.; RIBEIRO, I. (orgs.). O Português Afro-Brasileiro. Salvador: Edufba, 2009b. p. 295-318.

https://doi.org/10.7476/9788523208752

LUCCHESI, D. A diferenciação da língua portuguesa no Brasil e o contato entre línguas. Estudos de Lingüística Galega, Santiago de Compostela, n. 4, p. 45-65, 2012.

LUCCHESI, D. O contato entre línguas na história sociolinguística do Brasil. In: VALENTE, A. (Org.). Unidade e Variação na Língua Portuguesa: suas representações. São Paulo: Parábola. p. 80-100. 2015a.

LUCCHESI, D. Língua e sociedade partidas: a polarização sociolinguística do Brasil. São Paulo: Contexto, 2015b.

LUCCHESI, D. Por que a crioulização aconteceu no Caribe e não aconteceu no Brasil? Condicionamentos sócio-históricos. Gragoatá, v. 24, n. 48, p. 227-255, 2019. https://doi.org/10.22409/gragoata.2019n48a33628

LUCCHESI; D.; BAXTER, A.; RIBEIRO, I. (orgs.). O Português Afro-Brasileiro. Salvador: Edufba, 2009. https://doi.org/10.7476/9788523208752

LUCCHESI, D.; BAXTER, A.; SILVA, J. A. A. A concordância verbal. In: LUCCHESI; D.; BAXTER, A.; RIBEIRO, I. (orgs.). O Português Afro-Brasileiro. Salvador: Edufba, 2009. p. 331-372. https://doi.org/10.7476/9788523208752

LUCCHESI, D.; MACEDO, A. A variação na concordância de gênero no português de contato do Alto Xingu. Papia, Brasília, v. 9, p. 20-36, 1997.

MAHER, T. M. Ser professor sendo Índio: questão de língua(gem) e identidade. Campinas: Pontes, 1996. 
MAHER, T. M. Sendo índio em português... In: SIGNORINI, I. (Org.). Língua(gem) e identidade: elementos para uma discussão no campo aplicado. Campinas: Mercado de Letras/Fapesp, 1998. p. 115-38.

MAIA. M. A revitalização de línguas indígenas e seu desafio para a educação intercultural bilíngue. Tellus, ano 6, n. 11, p. 61-76, 2006. https://doi.org/10.20435/tellus.v0i11.105

MATRAS, Y. Contact, Convergence and Typology. In: HICKEY, R. (ed.). The Handbook of Language Contact. Chichester: Wiley-Blackwell, 2010. p. 66-85. https://doi.org/10.1002/9781444318159.ch3

MATTOS E SILVA, R. V. Sete Estudos sobre o Português Kamayurá. Salvador: Centro Editorial e Didático da UFBS, 1988.

MICHAELIS, S. Predicative noun frase. In: MICHAELIS, S.; MAURER, P.; HASPELMATH, M.; HUBER, M. (Eds.). The Atlas of Pidgin \& Creole Language Structures. Oxford: Oxford University Press, 2013. p. 290-294.

PERDUE, C. Adult Language Acquisition; Cross-Linguistic Perspectives. Vol. 1: Field Methods. Cambridge: Cambridge University Press, 1993a.

PERDUE, C. Adult Language Acquisition; Cross-Linguistic Perspectives. Vol. 2: The Results. Cambridge: Cambridge University Press, 1993b.

RODRIGUES, Aryon. A Classificação do Tronco Tupi. Revista de Antropologia, v. 12, n. $1 / 2$, p. 99-104, 1986.

RODRIGUES, A. Relações internas na família linguística Tupi-Guarani. Revista Antropológica, v. 27/28, p. 33-53, 1984/85.

RODRIGUES, A. Línguas indígenas: 500 anos de descobertas e perdas. DELTA, v. 9, n. 1, p. 83103, 1993.

RODRIGUES, A. D.; DIETRICH, W. On the linguistic relationship between mawe and tupiguarani. Diachronica, Amsterdam, v. XIV, n. 2, p. 265-304, 1997.

https://doi.org/10.1075/dia.14.2.04rod

ROMAINE, S. Contact and Language Death. In: HICKEY, R. (ed.). The Handbook of Language Contact. Chichester: Wiley-Blackwell, 2010. p. 320-339.

https://doi.org/10.1002/9781444318159.ch16

SILVA, R. G. P. da. Estudo Morfossintático da Língua Sateré-Mawé. 2010. 247 f. Tese (Doutorado em Linguística) - Universidade Estadual de Campinas, Campinas, 2010.

SIMAS, H. C. P.; FERNANDES, T. N.; SILVA, A. R. A Língua sateré-mawé em contexto urbano. In: BARTOLI, E.; MUNIZ, C.; AlBUQUerQUE, R. (orgs). Parintins: Sociedade, Território e Linguagens. Manaus: EDUA, 2016. p. 161-178.

SOCIOAMBIENTAL. Os filhos do Guaraná. Disponível em: https://pib.socioambiental.org/pt/Povo:Sater\%C3\%A9 Maw\%C3\%A9\#Os filhos do Guaran. C3.A1. Acesso em: 28 set. 2020.

TEIXEIRA, P. Sateré-Mawé: Retrato de um povo indígena. Manaus: UFAM, 2005. 
TRUDGILL, P. Sociolinguistic typology and complexification. In: SAMPSON, Geoffrey; GIL David; TRUDGILL, Peter (eds.). Language complexity as an evolving variable. Oxford: Oxford University Press, 2009. p. 97-108. https://doi.org/10.1002/9781444318159.ch15

TRUDGILL, P. Contact and Sociolinguistic Typology. In: HICKEY, R. (ed.). The Handbook of Language Contact. Chichester: Wiley-Blackwell, 2010. p. 299-319.

UGGÉ, H. Bonitas Histórias Sateré-Maué. Manaus: Governo do Estado do Amazonas, SEDUC, s/d.

WINFORD, Donald. An introduction to Contact Linguistic. Oxford: Blackwell, 2003.

Recebido em: 20/04/2020.

Aceito em: 06/08/2020. 